\title{
Long-term work retention after treatment for cancer: a systematic review and meta-analysis
}

\author{
Angela GEM de Boer ${ }^{1} \cdot$ Steffen Torp ${ }^{2}$ - Adela Popa $^{3}$ - Trine Horsboel ${ }^{4}$. Vesna Zadnik ${ }^{5}$ - Yakir Rottenberg ${ }^{6}$. \\ Edit Bardi ${ }^{7} \cdot$ Ute Bultmann ${ }^{8} \cdot$ Linda Sharp ${ }^{9}$ (i)
}

Received: 3 December 2019 / Accepted: 29 January 2020 / Published online: 11 March 2020

(C) The Author(s) 2020

\begin{abstract}
Purpose Almost half of people diagnosed with cancer are working age. Survivors have increased risk of unemployment, but little is known about long-term work retention. This systematic review and meta-analysis assessed work retention and associated factors in long-term cancer survivors.

Methods We searched Medline/Pubmed, Embase, PsychINFO, and CINAHL for studies published 01/01/2000-08/01/2019 reporting work retention in adult cancer survivors $\geq 2$ years post-diagnosis. Survivors had to be in paid work at diagnosis. Pooled prevalence of long-term work retention was estimated. Factors associated with work retention from multivariate analysis were synthesized.

Results Twenty-nine articles, reporting 21 studies/datasets including 14,207 cancer survivors, were eligible. Work retention was assessed 2-14 years post-diagnosis. Fourteen studies were cross-sectional, five were prospective, and two contained both crosssectional and prospective elements. No studies were scored as high quality. The pooled estimate of prevalence of long-term work retention in cancer survivors working at diagnosis was 0.73 (95\% CI $0.69-0.77)$. The proportion working at $2-2.9$ years was 0.72 ; at $3-3.9$ years 0.80 ; at $4-4.9$ years 0.75 ; at $5-5.9$ years 0.74 ; and $6+$ years 0.65 . Pooled estimates did not differ by cancer site, geographical area, or study design. Seven studies assessed prognostic factors for work retention: older age, receiving chemotherapy, negative health outcomes, and lack of work adjustments were associated with not working.

Conclusion Almost three-quarters of long-term cancer survivors working at diagnosis retain work.

Implications for Cancer Survivors These findings are pertinent for guidelines on cancer survivorship care. Professionals could focus support on survivors most likely to have poor long-term work outcomes.
\end{abstract}

Keywords Cancer $\cdot$ Work retention $\cdot$ Employment $\cdot$ Work ability $\cdot$ Return-to-work $\cdot$ Longitudinal studies $\cdot$ Prospective studies · Meta-analysis

Electronic supplementary material The online version of this article (https://doi.org/10.1007/s11764-020-00862-2) contains supplementary material, which is available to authorized users.

Linda Sharp

linda.sharp@ncl.ac.uk

1 Coronel Institute of Occupational Health, Amsterdam Public Health Research Institute, Amsterdam UMC, University of Amsterdam, Amsterdam, The Netherlands

2 Department of Health, Social \& Welfare Studies, University College of South-Eastern Norway, Notodden, Norway

3 Lucian Blaga University of Sibiu, Sibiu, Romania

4 The Danish Cancer Society Research Center, Copenhagen, Denmark
5 Institute of Oncology Ljubljana, Ljubljana, Slovenia

6 Sharett Institute of Oncology, Hadassah-Hebrew University Medical Center, Jerusalem, Israel

7 Kepler Universitäts Klinikum, Linz, Austria

8 University Medical Center Groningen, University of Groningen, Groningen, the Netherlands

9 Population Health Sciences Institute, Newcastle University Centre for Cancer, Newcastle University, Newcastle upon Tyne, United Kingdom 


\begin{tabular}{|c|c|}
\hline \multicolumn{2}{|c|}{ Abbreviations } \\
\hline \multicolumn{2}{|c|}{ CANWON CAI } \\
\hline CI & confidence interval \\
\hline $\mathrm{df}$ & degrees of freedom \\
\hline MINORS & $\begin{array}{l}\text { Methodological Index for } \\
\text { Non-Randomised Studies }\end{array}$ \\
\hline PRISMA & $\begin{array}{l}\text { Preferred Reporting Items } \\
\text { for Systematic Reviews and Meta-Analyses }\end{array}$ \\
\hline $\mathrm{RR}$ & relative risk \\
\hline
\end{tabular}

\section{Introduction}

The sustained improvements in detection and treatment of many types of cancer have steadily increased life expectancy after cancer treatment [1]. During the next decade, a further rapid increase in the number of new cancer diagnoses in the population and a growing number of cancer survivors are expected [1].

Almost half of the people diagnosed with cancer are of working age [2] and it is therefore likely that the prevalence of cancer survivors in the work force will increase. In addition, the retirement age is rising in many countries, implying that more cancer survivors will be part of the working population [3].

For both cancer survivors themselves and society, returning to work is important. Survivors often regard returning to work as regaining normality and self-respect [4]. It contributes to their quality of life [5] and provides them with financial security [6]. From the viewpoint of the ageing society, it is an economic and social necessity to encourage survivors to return to work whenever possible [7].

Cancer survivorship is associated with a range of enduring physical and psychological effects including long-lasting fatigue $[8,9]$, depression $[9,10]$, physical complaints $[9,11]$, and neurocognitive limitations $[9,12,13]$. These long-term outcomes of cancer treatment can have persistent impact on the work ability of survivors [14]. As a result, cancer survivors have been shown to have an increased risk of unemployment compared to the general population in long-term follow-up studies [15-17].

Several reviews on the impact of cancer treatment on shortterm work outcomes have been published [18-20]. These reviews showed return to work rates between 39 and $93 \%$ within 1-2 years after diagnosis. However, the employment pathways of cancer survivors could change after this point because treatment for cancer can, increasingly, be a long process (taking a year or more) and survivors can have persistent longterm effects which may last well beyond 2-year post-diagnosis [21]. However, the long-term effects of cancer treatment on work outcomes have not been systematically reviewed. In addition, the influence of prognostic factors on long-term work outcomes has not been synthesized.
A systematic review on the long-term work status of cancer survivors would be of value both for helping shape expectations of new cancer patients regarding likely long-term outcomes (including work outcomes), and in psychosocial survivorship care, when counselling survivors on the long-term psycho-oncological outcomes after treatment [22]. This type of information can therefore help improve survivors' quality of life by preventing work loss and distress.

The aims of the current study are therefore (i) to systematically assess long-term work retention among cancer survivors 2 years and more after diagnosis and (ii) to assess associated factors for work retention in long-term cancer survivors.

\section{Materials and methods}

\section{Search strategy}

We followed the Preferred Reporting Items for Systematic Reviews and Meta-Analyses (PRISMA) guidelines in conducting this review and preparing the manuscript [23]. We searched four databases (Medline [Pubmed], Embase, PsychINFO, CINAHL) to identify studies reporting workforce retention in long-term cancer survivors, published from 01/01/ 2000 to $08 / 01 / 2019$. We defined long-term survivors as those who were at least 2 years from diagnosis [24]. Combinations of disease-related, work-related, and survivor-related search terms were used (Supplementary Table S1). Disease-related terms included cancer, neoplasm, carcinoma, tumour, oncology, radiotherapy and chemotherapy; work-related terms included employment, unemployment, retirement, sick leave, sickness absence, absenteeism, presenteeism, work, occupation, work ability, work disability, disability management, rehabilitation and vocational; and survivor-related terms included survivor, survival, and long-term. Wildcards and alternative spellings were used where appropriate. Only full papers published in peer-reviewed journals were eligible; we did not include conference abstracts or the gray literature, the former because abstracts rarely contain sufficient detail to be able to determine eligibility (or appraise quality) and the latter because such studies are difficult to identify systematically. Reference lists from reviews of cancer and work identified in the electronic searches and of eligible papers were scrutinized to identify any potentially eligible articles which might have been missed by the electronic searches.

\section{Eligibility criteria}

To be included, papers had to include survivors who were all at least 2-years post-diagnosis. If study participants were a range of times from diagnosis (e.g., 6 months to 3 years), then the group of long-term survivors (at least 2-years post-diagnosis) had to be reported separately. Studies were eligible if they 
included cancers at any site (invasive or in situ) diagnosed in adults (defined as those aged 18 and older); studies of cancers diagnosed in children or adolescents were excluded as their employment outcomes may differ from those of survivors diagnosed in adulthood. All survivors in the studies needed to be employed or in paid work at the time of diagnosis (either for an employer or self-employed); studies where survivors were in the labor market at diagnosis but were not all employed/ working (e.g., some were unemployed or job seeking), and the group employed/working were not reported separately, were not eligible. In terms of outcomes, studies had to report a measure of work retention (e.g., percentage employed/unemployed/working or percentage return to work) at 2-years postdiagnosis and/or later time-points. Our primary interest was in the proportion of survivors who were working long term; therefore, if a study reported survivors by work status category (e.g., on sick leave, retired, working) or multiple measures of work retention, we abstracted the figure for those who were working (i.e., back in the workplace) at the time the outcome was assessed. Studies which reported raw figures such as numbers or percentages of work retention were included and those reporting only odds ratios or relative risks were excluded. Quantitative cross-sectional or prospective observational studies, with or without a control/comparison groups, were eligible, as were observational studies nested within randomized controlled trials. Trials of vocational or rehabilitation interventions were excluded as the return to work experiences of participants may not have been typical of those of the base population. In addition, we excluded studies of survivors of occupational cancers because their return to work experiences may not be typical of all survivors. Only studies where the base population was known were included. To have a reasonable degree of precision in the estimates of work retention, we excluded studies where outcome data was available on less than 50 individuals. No language limits were placed on the search.

\section{Data extraction}

Two of the authors independently screened each title and abstract. Full text of papers considered potentially eligible for inclusion by either or both reviewers were read independently by the same two reviewers and their suitability for inclusion assessed. The reviewers then compared results and discussed any discrepancies; a third author (AdB or LS) was called on in the event of disagreement. When uncertainty about eligibility remained, authors of papers were contacted; if they did not respond after a reasonable time, the paper was excluded.

Data abstraction from eligible papers was done independently by two authors. Information extracted on study characteristics included (1) study location (country); (2) study design; (3) study population including diagnosis, sex, age; (4) time-points at which outcomes were assessed; and (6) which outcome(s) were assessed and how. Information was abstracted on work retention (preferentially percentage working or returned to work; percentage employed otherwise; percentage unemployed was converted into percentage employed). Information was also abstracted on any risk factors for work retention (categorized as patient-related, clinical or work-related) considered. If multivariable analyses of risk factors were reported, results of these were abstracted and reported. Finally, details of any other work-related outcomes reported (e.g., income, working hours) were extracted.

\section{Analysis}

Meta-analysis was conducted in Stata 15 [College Station, Texas, USA], using the metaprop_one command [25], fitting a logistic-normal random effects model with inverse-variance weights and the Freeman-Tukey double arcsine transformation. The pooled proportion working or employed was computed across all studies. Results for studies which reported the inverse of the outcome of interest (e.g., unable to work) were subtracted from 100 before inclusion. In the primary analysis, for studies which reported multiple time-points, results from the earliest time-point post-diagnosis were used; a sensitivity analysis was conducted in which results for the last time-point postdiagnosis were used instead. Pooled proportions were also computed for a range of time windows post-diagnosis: 22.9 years, 3-3.9 years, 4-4.9 years, 5-5.9 years, and 6+ years. In these analyses, studies which reported results at multiple time-points were included in the analysis for each relevant time-point. Subgroup analysis was performed for cancer site, geographical area as defined by the World Health Organization [26], study design, and sampling frame for the cancer population. All tests of statistical significance were two-sided.

\section{Quality appraisal}

Full papers of eligible studies were critically appraised, by two authors (AdB, LS), using the Methodological Index for NonRandomised Studies (MINORS) [27]. Where multiple papers were available from the same study/using the same dataset, we appraised the paper which included data from a comparative group or, failing that, the earliest published paper. Studies were scored on 12 items, eight of which applied to all studies: the aim of the study, inclusion and retention rate, prospective data collection, employment endpoints, unbiased assessment of endpoints, follow-up time after diagnosis, loss to follow-up, and prospective calculation of sample size. Four additional items applied only to those studies with control/comparison groups: comparable control group, contemporary control group, baseline equivalence of groups, and adequate statistical analysis. Each study was scored $0 / 1 / 2$ for each item. Thus, the total possible score for a non-comparative study was 16 and for a comparative study was 24 . High quality was considered a score of $\geq 16 / 24$ [2]. 


\section{Results}

\section{Study selection}

Figure 1 shows the number of papers identified, screened, and included. After removal of duplicates, the initial searches yielded 5334 records. After screening of titles and abstracts, 229 articles remained. Following full-text review of these, 29 articles were deemed eligible. These final 29 articles reported findings from 21 different studies or datasets (Table 1) [28-56].

\section{Study characteristics}

Of the 21 studies, six were undertaken in the USA [29, 31, 35, $47,48,51]$, three in the Netherlands $[43,54,56]$, two each in Brazil [39, 55], Canada [36, 40], France [44, 52], and Norway
[33, 38], and one each in Ireland [46], Israel [34], Sweden [37], and UK [28]. Fourteen studies were cross-sectional $[28,31,34,38,40,43,44,46-48,51,52,55,56]$, five were prospective [29, 33, 35, 36, 39], and two contained both crosssectional and prospective elements [37, 54]. Four studies included external comparison groups: one recruited controls matched to cases [40], two selected comparison populations from existing panel or labor market surveys [48, 52], and one used administrative data to identify the population without cancer [36]. Eleven studies used a population-based cancer registry $[28,31,35,40,43,46,47]$ or administrative data $[34,36,44,52]$ as the sampling frame for survivors, with the other ten studies recruiting from hospital or clinical sources [29, 33, 37-39, 48, 51, 54-56]. In eight studies, survivors of a variety of cancers were included [28, 31, 36, 43, $44,48,51,52]$; six studies included only breast cancer survivors [29, 34, 35, 37, 39, 40]; three included head and neck
Fig. 1 Flow diagram of included studies
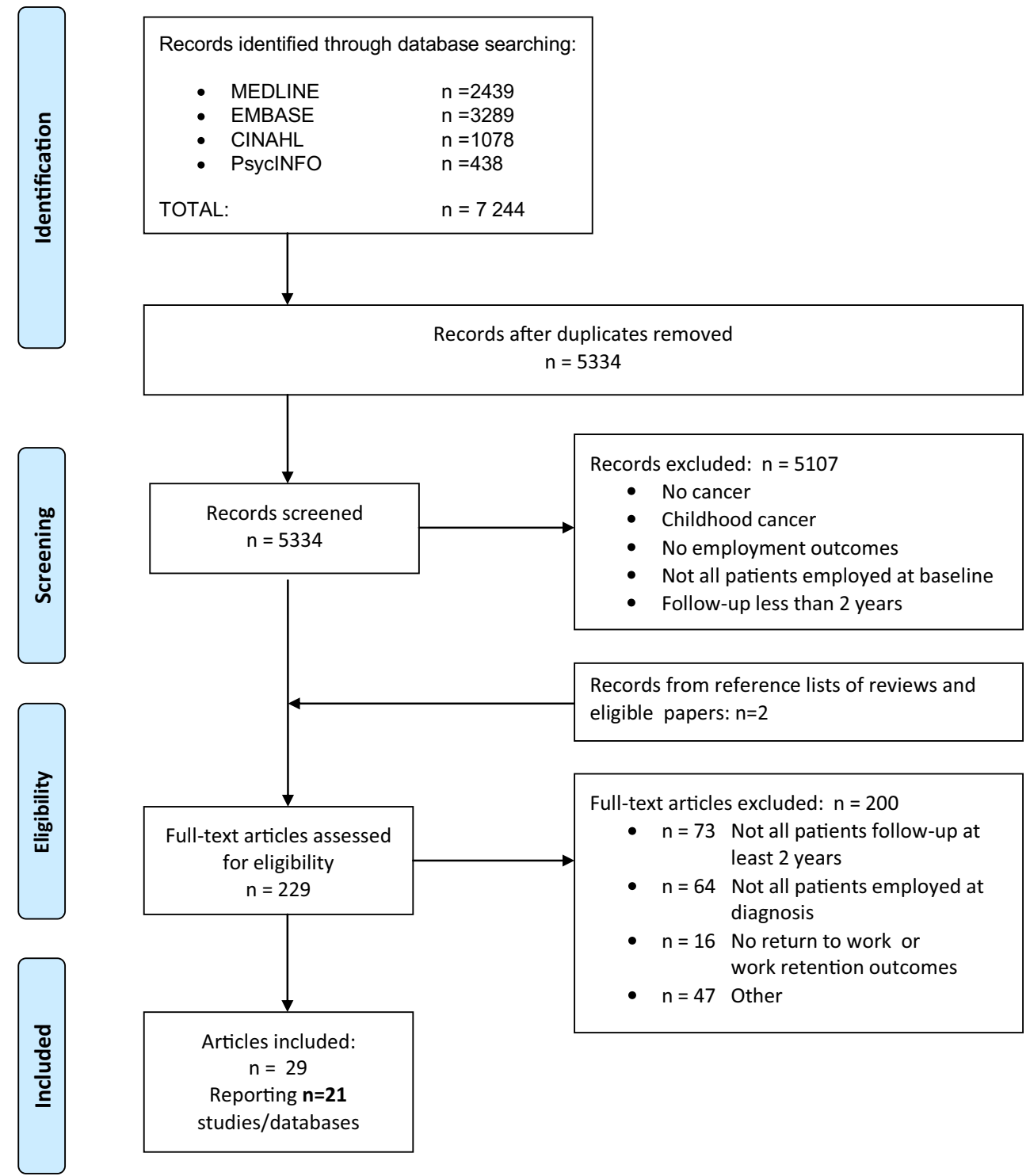

$$
n=29
$$

Reporting $\mathbf{n}=\mathbf{2 1}$

studies/databases 


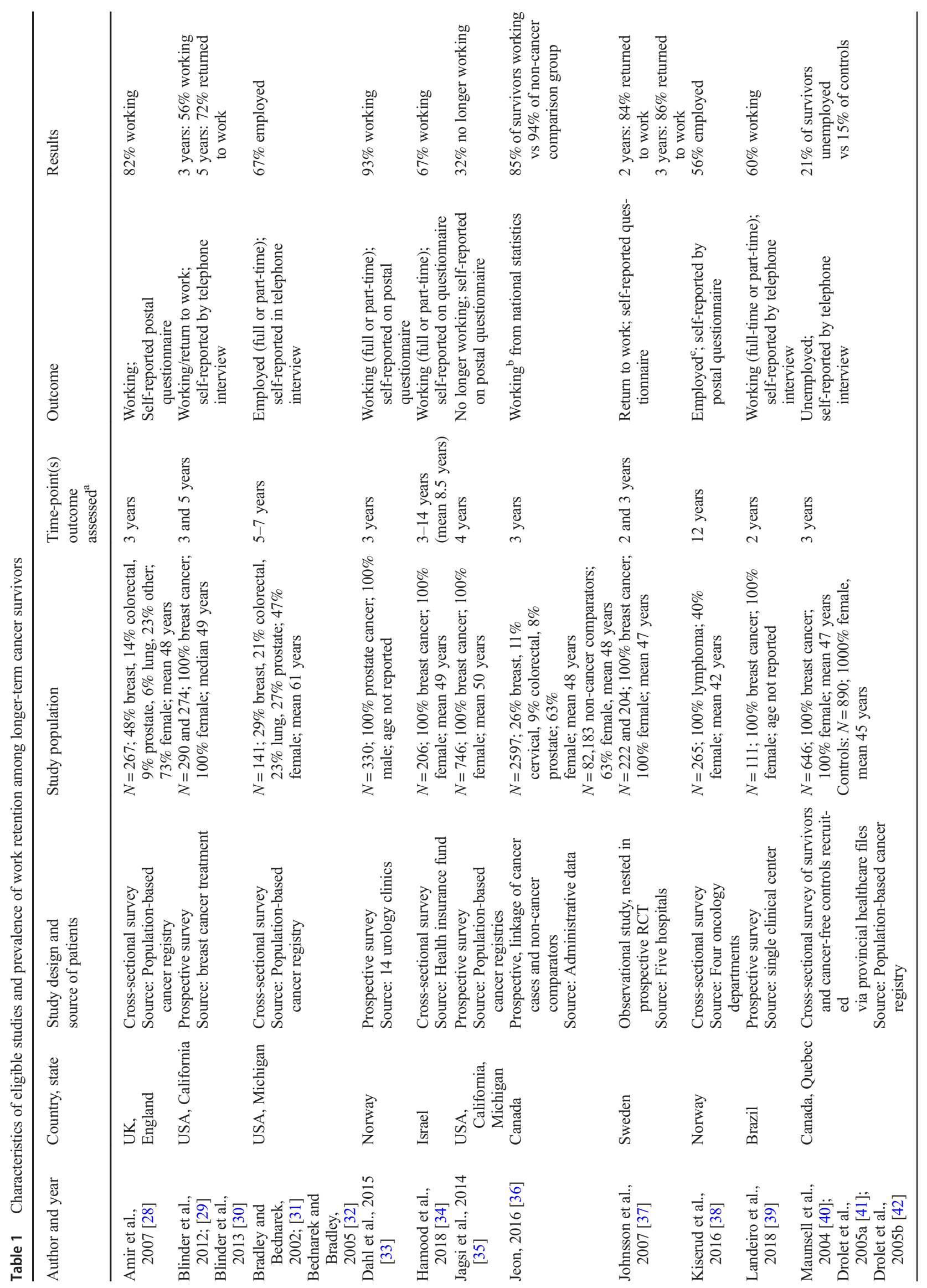




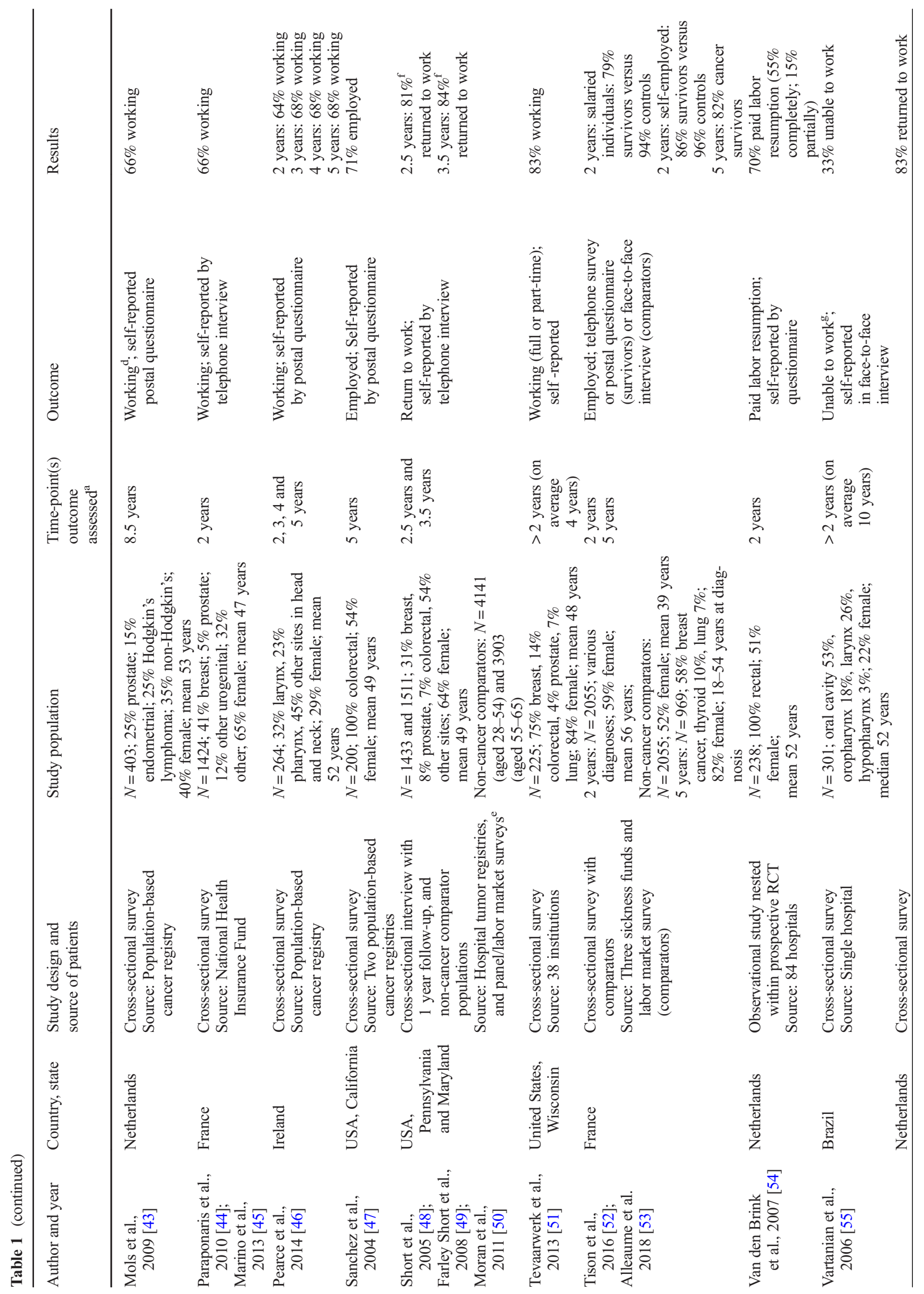


cancers only (albeit at multiple sites within the head and neck) $[46,55,56]$; two included colorectal cancers only [47, 54]; one included hematological cancers only [38]; and one included prostate cancer only [33].

Sample sizes ranged from 53 to 2597, with 14,207 survivors included in total. The mean age of survivors varied from 42 to 61 years. Work retention was described in terms of working in 16 studies ("working" in 10 studies [28, 29, 33, $34,36,39,43,44,46,51]$; "returned to work" in three [37, 48, 56]; "paid labour resumption" in one [54]; "no longer working" in one [35]; "unable to work" in one [55]) and in terms of employment in five studies ("employed" in four studies [31, $38,47,52]$; and "unemployed" in one [40]).

Work outcomes were assessed by self-report in 20 studies and from administrative data in one study [36]. The time at which work retention was assessed ranged from 2 to 14 years post-diagnosis. Five studies (one prospective [29], three crosssectional [46, 48, 52], and one mixed [37]) reported work retention at multiple time points.

\section{Quality assessment}

Of the non-comparative studies, for which the maximum possible score was 16 , ten scored $\leq 8[28,34,38,43,44,46,47$, $51,55,56]$ and seven scored 9 or more $[29,31,33,35,37,39$, 54] (Supplementary Table S2). The four studies with a comparison population scored in the range 12-15 out of a maximum score of 24 [36, 40, 48, 52]. As a result, no studies scored as high quality mainly due to lack of non-cancer control groups. Across studies, the areas where studies scored poorly were lack of prospective data collection, unclear endpoints, failure to report a priori sample size calculation, and failure to report loss to follow-up.

\section{Workforce retention among long-term survivors}

The pooled estimate of the proportion of survivors working at $\geq 2$ years post-diagnosis was 0.73 (95\%CI 0.69-0.77) (Fig. 2). Heterogeneity was significant $\left(I^{2}=96.4 \%\right)$. In the sensitivity analysis, in which the final (rather than earliest) time-point was included for the five studies which reported work retention at multiple time-points $[30,37,46,48,52]$, the pooled estimate was 0.75 (95\% CI $\left.0.70-0.79, I^{2}=96.0 \%\right)$.

The proportion working at different time-points after diagnosis was as follows: $2-2.9$ years (reported in seven studies): 0.72 (95\%CI $0.66-0.77) ; 3-3.9$ years (8 studies): 0.80 (95\%CI $0.74-0.86) ; 4-4.9$ years (4 studies): 0.75 (95\%CI $0.67-0.83$ ); $5-5.9$ years (4 studies): 0.74 (95\%CI $0.66-$ $0.81)$; $6+$ years (5 studies): 0.65 (95\%CI $0.60-0.69$ ).

Figure 2 shows that there was no significant difference in the pooled estimate between subgroups defined by cancer site (mixed sites: 0.76 (95\%CI 0.69-0.82); breast: 0.70 (95\%CI 0.61-0.78); head and neck: 0.70 (95\%CI $0.61-0.77$ ); 


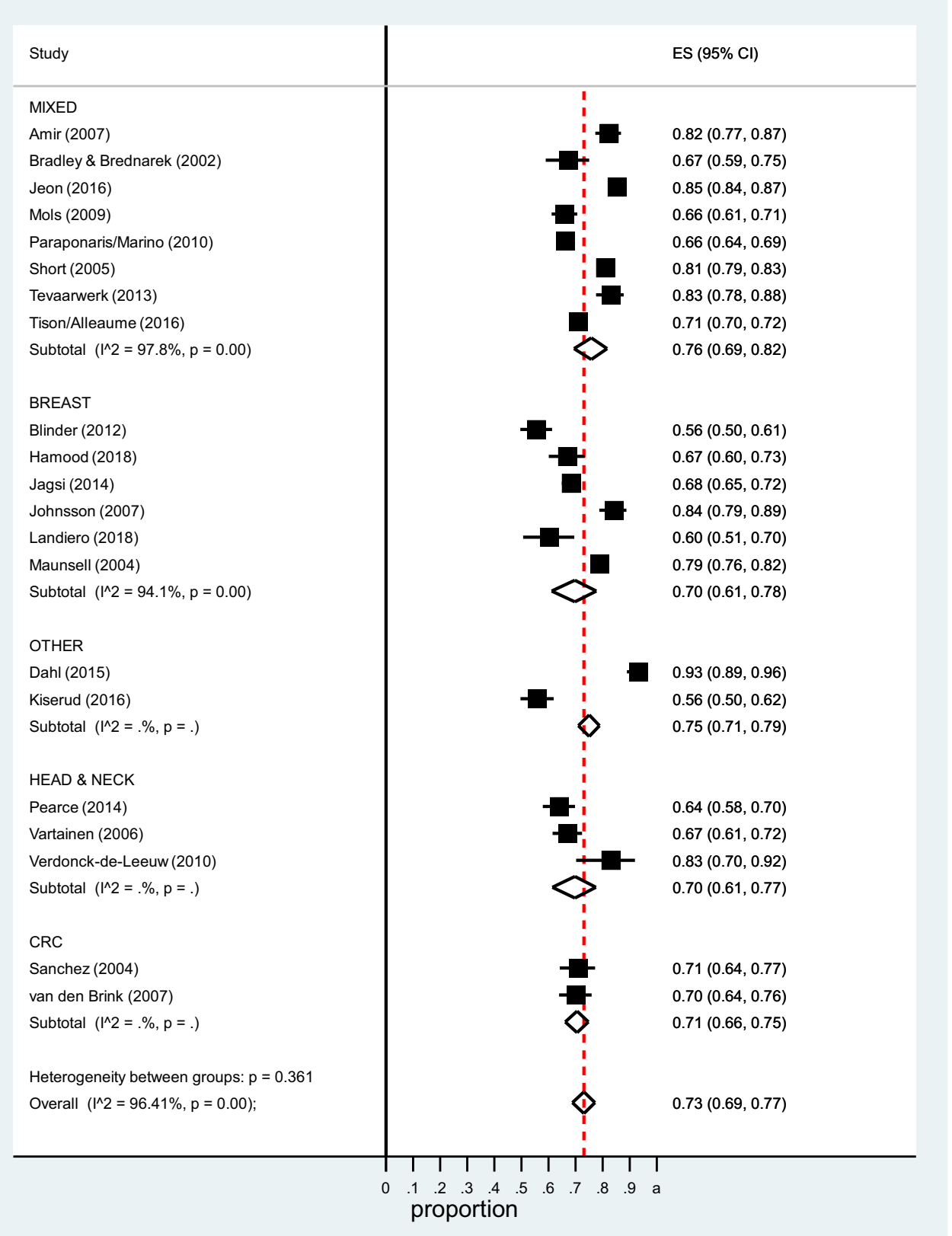

Fig. 2 Proportion of survivors who have returned to work $2+$ years post-diagnosis by cancer site

colorectal: 0.71 (95\% CI 0.66-0.75); and other individual sites: 0.75 (95\%CI 0.71-0.79); subgroup heterogeneity Chi-square $=4.34,4 d f, P=0.36)$. By geographical area (Fig. 3), the pooled estimates were Europe 0.74 (95\% CI 0.69-0.79), North America 0.75 (95\%CI 0.68-0.81), and elsewhere 0.66 (95\% CI $0.62-0.70)$. There was no difference in the pooled estimate by study design (crosssectional: 0.72 (95\%CI $0.68-0.76)$; prospective: 0.75 (95\% CI 0.65-0.84); subgroup heterogeneity Chisquare $=0.37,1 d f, P=0.54$ ) or data source (population-based/administrative: 0.72 (95\%CI $0.67-0.77)$; clinical: 0.74 (95\%CI $0.66-0.82)$; subgroup heterogeneity
Chi-square $=0.21,1 d f, P=0.65$ ) (Supplementary Figures S1 and S2).

\section{Studies with non-cancer comparators}

The five articles describing the four studies which included comparison groups reported lower long-term work retention among survivors than comparators [36, 40, 49, 50, 52]. In Canada, Maunsell et al. found that the relative risk of unemployment at 3 years was significantly higher among survivors $(\mathrm{RR}=1.29,95 \% \mathrm{CI} 1.05-1.59)$ [40]. Also, in Canada, Jeon et al. reported that $85 \%$ of survivors were working at $25-47$ - 
Fig. 3 Proportion of cancer survivors who have returned to work $2+$ years post-diagnosis by geographical area

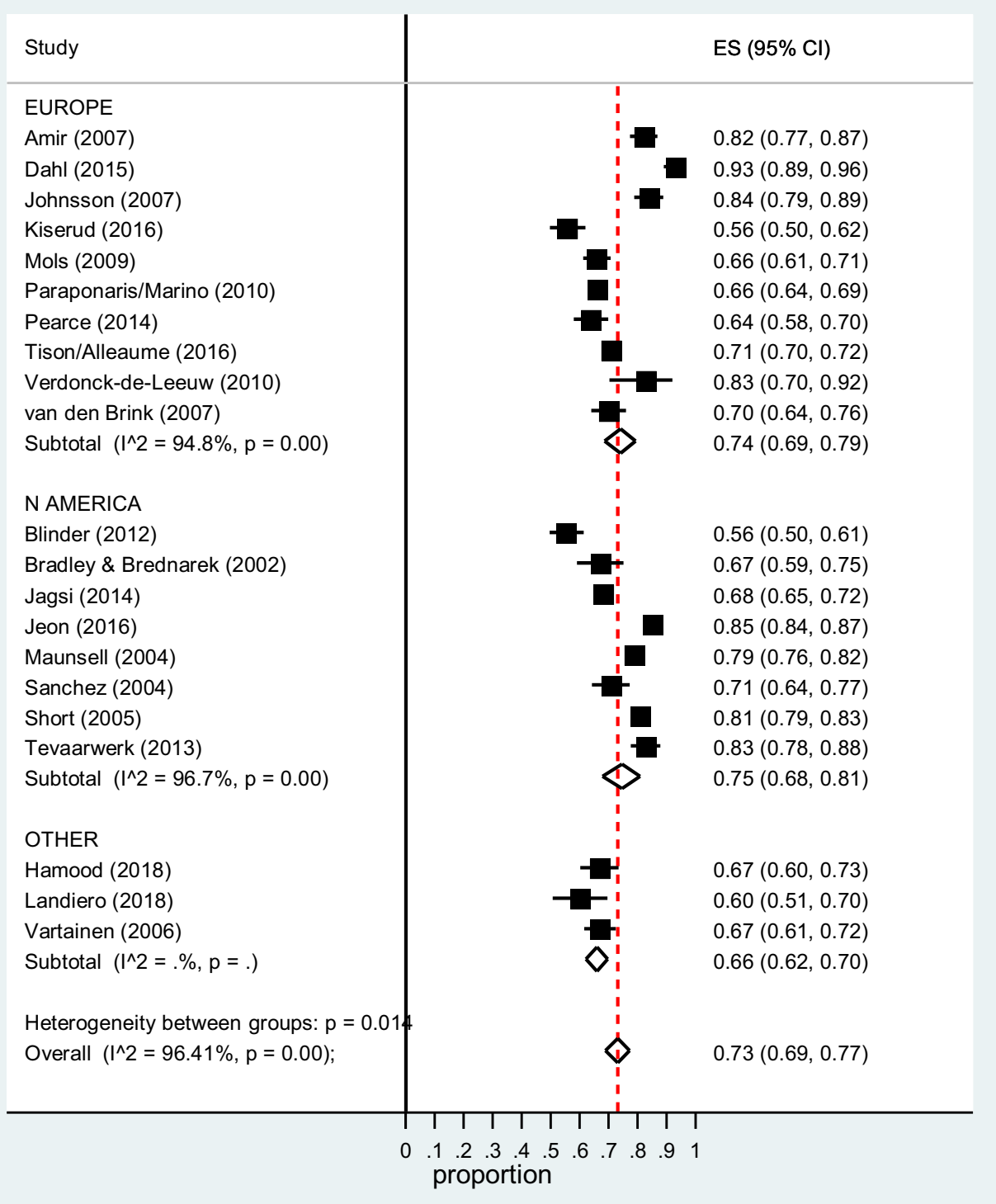

month post-diagnosis compared to $94 \%$ of comparators [36]. In France, compared to matched comparators, the percentage of survivors who were employed at 2-years post-diagnosis was lower among both salaried (79\% vs 94\%) and self-employed (86\% vs 96\%) individuals [52]. In the USA, the employment rate at 2-6-years post-diagnosis was 7-8\% lower for survivors aged 25-54 than age-matched comparators [50] and 4\% lower for survivors aged 55-65 than similarly aged comparators [49].

\section{Risk factors for work retention among long-term survivors}

Seven studies investigated patient-related, clinical, and/or work-related risk factors for work retention among longterm cancer survivors and analyzed them in a multivariate analysis [28, 29, 35, 39, 40, 52, 55] (Table 2).
Of the patient-related factors, older age [35, 40, 52] and lower income at diagnosis [39, 40, 52] were significantly associated with not returning to work in multivariate analyses in three studies. The clinical factors receiving chemotherapy $[35,52]$, having comorbidities [30, 35, 52], having a new cancer event [40, 52], having a poor prognosis [52, 55] or depression [39, 52], and the work-related factor lack of work adjustments $[35,39]$ were associated in multivariate analyses with not returning to work.

\section{Other work-related outcomes}

Sixteen studies reported other work-related outcomes among survivors (Table 3 ). Of the nine studies which examined changes in working hours among survivors [28, 33, 34, 39, 40, 43, $46,48,52]$, six studies reported that $12-52 \%$ of survivors who 
Table 2 Risk factors for work retention among longer-term cancer survivors

\begin{tabular}{|c|c|c|}
\hline Author and year & Risk factors assessed & Results $^{\mathrm{a}}$ \\
\hline Amir et al., 2007 [28] & $\begin{array}{l}\text { - Patient-related: gender, deprivation } \\
\text { - Clinical: surgery } \\
\text { - Work-related: length of sick leave }\end{array}$ & $\begin{array}{l}\text { Longer sick leave }(\mathrm{OR}=1.68,1.2-2.3) \text { and absence } \\
\text { of surgery }(\mathrm{OR}=0.28,0.08-0.9) \text { were significantly } \\
\text { associated with working } 3 \text { years after diagnosis }\end{array}$ \\
\hline $\begin{array}{l}\text { Blinder et al., } 2012 \text { [29]; } \\
\text { Blinder et al., } 2013 \text { [30] }\end{array}$ & $\begin{array}{l}\text { Patient-related: age, race/ethnicity, birthplace, } \\
\text { household income, adequate financial resources, } \\
\text { marital status, children living at home, seniors living } \\
\text { at home, education, acculturation, social support } \\
\text { - Clinical: comorbid conditions, stage at diagnosis, type } \\
\text { of surgery, breast reconstruction, axilliary node } \\
\text { dissection, chemotherapy, radiotherapy, endocrine } \\
\text { therapy } \\
\text { - Work-related: job type, full/part-time work at diagnosis }\end{array}$ & $\begin{array}{l}\text { Presence of comorbid conditions ( } \mathrm{OR}=0.25,0.08-0.7 \text { ) } \\
\text { was significantly associated with not returning to } \\
\text { work } 3-5 \text { years postdiagnosis }\end{array}$ \\
\hline Jagsi et al., 2014 [35] & $\begin{array}{l}\text { - Patient-related: age, race, education, family income, } \\
\text { marital status, area of residence, family income } \\
\text { - Clinical: comorbidities, stage at diagnosis, type of } \\
\text { surgery, chemotherapy, radiotherapy } \\
\text { - Work-related: full/part time work at diagnosis, } \\
\text { employment support (sick leave/flexible schedule) }\end{array}$ & $\begin{array}{l}\text { Older age at diagnosis }(\geq 56 \text { vs }<46: \text { OR }=1.42,1.03-1.9) \text {, } \\
\text { receipt of chemotherapy }(\mathrm{OR}=1.42,1.03-1.98), \\
\text { comorbidities }(\geq 2 \text { vs none: } \mathrm{OR}=2.16,1.6-2.9) \text {, and } \\
\text { lack of work adjustments (none vs sick leave and/or flexible } \\
\text { schedule vs: } \mathrm{OR}=1.33,1.1-1.6) \text { were significantly associated } \\
\text { with unemployment }\end{array}$ \\
\hline $\begin{array}{l}\text { Landeiro et al., } \\
2018 \text { [39] }\end{array}$ & $\begin{array}{l}\text { - Patient-related: education, age, changes in marital status, } \\
\text { - Clinical: health status, weight gain, depression, pain, } \\
\text { lymphedema, breast conserving surgery, breast } \\
\text { reconstruction, axillary dissection, chemotherapy, } \\
\text { radiotherapy, endocrine therapy, anti-HER2 therapy, } \\
\text { quality of life } \\
\text { - Work-related: changes in income, work adjustment, } \\
\text { employer discrimination, employer support }\end{array}$ & $\begin{array}{l}\text { Higher household income }(\mathrm{OR}=16.6,1.8-155) \text {, work adjustments } \\
\text { (OR 37.6, 3.31-427), breast conserving surgery (OR 9.8, } \\
\text { 2.0-47), not having depression (OR 14.3, 1.6-100), and not } \\
\text { having endocrine therapy (OR 9.1, 1.3-50) were significantly } \\
\text { associated with working at } 2 \text { years post-diagnosis }\end{array}$ \\
\hline $\begin{array}{l}\text { Maunsell et al., } 2004 \text { [40]; } \\
\text { Drolet et al., 2005a [41]; } \\
\text { Drolet et al., 2005b [42] }\end{array}$ & $\begin{array}{l}\text { - Patient-related: age, living with partner, children, } \\
\text { education, personal income } \\
\text { - Clinical: disease status since diagnosis (disease-free } \\
\text { vs recurrence/contralateral breast cancer); } \\
\text { radiotherapy, chemotherapy, hormone therapy, } \\
\text { affected nodes } \\
\text { - Work-related: union member, experience in job, } \\
\text { type of job, hours per week, value of work }\end{array}$ & $\begin{array}{l}\text { Significant predictors of not working at } 3 \text { years were: older } \\
\text { age }(50-59 \text { vs } 18-39 \text { OR }=4.62,2.2-9.5) \text {, lower personal income } \\
(<\$ 20,000 \text { vs } \geq \$ 50,000 \mathrm{OR}=3.18,1.6-6.3) \text {, new cancer event } \\
(\mathrm{OR}=2.14,1.5-3.1) \text {, union membership (union membership } \\
\text { yes vs no } \mathrm{OR}=1.88,1.3-2.7 \text {; self-employed vs not union } \\
\text { member OR }=0.60,0.3-1.05) \text {, and value of work since } \\
\text { diagnosis (decreased vs increased: } \mathrm{OR}=1.83,1.1-3.0)\end{array}$ \\
\hline $\begin{array}{l}\text { Tison et al., } 2016 \text { [52]; } \\
\text { Alleaume et al. } 2018 \text { [53] }\end{array}$ & $\begin{array}{l}\text { - Patient-related: marital status, gender, age, } \\
\text { dependent children } \\
\text { - Clinical: cancer prognosis, adverse cancer event, } \\
\text { chemotherapy, radiotherapy, comorbidities, mental } \\
\text { health, chronic neuropathic pain } \\
\text { - Work-related: employment sector at diagnosis, } \\
\text { socio-professional status, wages at diagnosis, } \\
\text { full-time/part-time at diagnosis, type of employment } \\
\text { contract, self-employed versus employee, business sector }\end{array}$ & $\begin{array}{l}\text { Older age, not having children, and poor cancer prognosis, were } \\
\text { significantly related to not working at } 2 \text { years after cancer diagnosis. } \\
\text { Age } 18-39 \text { (OR } 1.69,1.00-2.9 \text { ) or age } 50-54 \text { (OR } 1.65,1.06-2.6 \text { ), } \\
\text { not having children (OR 2.1, 1.3-3.4), poor cancer prognosis } \\
\text { (OR 3.6, 1.6-8.2), adverse cancer event (OR 2.1, 1.3-3.3), } \\
\text { chemotherapy (OR 1.6, 1.1-2.4), comorbidities (OR 2.0, } \\
\text { 1.2-3.4), mental health (OR 0.96, 0.95-0.98), chronic } \\
\text { neuropathic pain (OR 2.6, 1.7-3.9), private sector (OR 2.5, } \\
\text { 1.5-4.3), execution function (OR 2.2, 1.4-3.2), and higher } \\
\text { wages at diagnosis (OR 1.01, 0.99-1.03) were significantly } \\
\text { related to leaving employment at } 5 \text { years after cancer diagnosis }\end{array}$ \\
\hline $\begin{array}{l}\text { Vartanian et al. } \\
2006[55]\end{array}$ & $\begin{array}{l}\text { - Patient-related: gender, age, alcohol use, education, } \\
\text { pain, quality-of-life score } \\
\text { - Clinical: cancer site, stage, treatment, } \\
\text { permanent tracheostomy }\end{array}$ & $\begin{array}{l}\text { More advance stage (VI vs I OR }=3.5,1.5-8.1) \text {, alcohol use before } \\
\text { treatment }(\mathrm{OR}=2.6,1.3-5.2) \text {, and lower education (high school } \\
\text { or college vs illiterate } \mathrm{OR}=0.2,0.5-0.8) \text { were significantly } \\
\text { associated with being unable to work }>2 \text { years post-diagnosis }\end{array}$ \\
\hline
\end{tabular}

${ }^{\text {a }}$ Only results significant in multivariable analyses are reported

had returned to work had reduced their working hours compared to before diagnosis $[28,39,40,43,46,52]$. One study reported that survivors worked fewer hours than similarly aged people without cancer [48]. In three studies, the proportion of survivors working part-time had increased and/or the proportion working full-time had decreased [33, 34, 40].

Five studies reported on other changes in survivors' work situations. There was no difference in the proportion of breast cancer survivors (19\%) who had changed job at 3 years compared to non-cancer comparators [40]. Another study of a mixed group of survivors reported that $8 \%$ had changed employer at 3 years [28]. Three studies reported that a proportion of survivors (13-55\%) had had to reduce workload, change their working schedule, or make adaptations due to cancer $[31,38,56]$.

Three studies described income post-diagnosis [36, 39, 40]. In one, during 25-47-month post-diagnosis, survivors earned 9\% less than comparators [36] and, in another, $21 \%$ of 
Table 3 Other work-related outcomes among longer-term cancer survivors

\begin{tabular}{lll}
\hline Author and year & $\begin{array}{l}\text { Work-related outcomes } \\
\text { assessed }\end{array}$ & Results
\end{tabular}

\begin{tabular}{ll}
\hline Amir et al., 2007 [28] & Change in working hours \\
• Change in place of work
\end{tabular}

- Perception of work

Bradley and Bednarek, 2002 [31]; • Change in work schedule Bednarek and Bradley, 2005 [32] Dahl et al., 2015 [33]

- Reduced working hours

- Influence of prostate cancer on working life

Hamood et al., 2018 [34]

- Change in working hours

Jagsi et al., 2014 [35]

Jeon, 2016 [36]

Kiserud et al., 2016 [38]

- Work changes
due to cancer
- Work ability

Landeiro et al., 2018 [39]

Maunsell et al., 2004 [40];

Drolet et al., 2005a [41];

Drolet et al., 2005b [42]

Mols et al., 2009 [43]

Paraponaris et al., 2010 [44];

Marino et al., 2013 [45]

Pearce et al., 2013 [46]

Sanchez et al., 2004 [47]

Short et al., 2005 [48]; Farley

Short et al., 2008 [49];

Moran et al., 2011 [50]

Tison et al., 2016 [52];

Alleaume et al., 2018 [53]

Verdonck-de Leeuw

et al., 2010 [56]
- Seeking work

- Income

anges

- Change in working hours - Income

- Perceived employer discrimination

- Change in working hours

- Change in job

- Income

- Sickness absence

- Change in working hours

- Sickness absence

- Change in working hours

- Sickness absence

- Hours worked

- Change in working hours

- Change in work
- $18 \%$ of survivors who took $<6$ months sick leave, and $43 \%$ of those who took $\geq$ 18 months sick leave, changed their working hours compared to before diagnosis

- $8 \%$ of survivors who had returned to work changed to a different place of work

- $19 \%$ of survivors who returned to work reported that their overall working life had deteriorated due to cancer

- $54 \%$ of survivors reduced their workload/working schedule at least once because of cancer

- $66 \%$ of survivors worked full-time at 3 years compared to $75 \%$ at diagnosis

- $34 \%$ of survivors reported that prostate cancer had influence their working life to some/great extent. In multivariable analysis among men active in the workforce, adjuvant/salvage treatment, chronic fatigue, physical work and bother with urinary leakage were significantly associated with believing prostate cancer had influenced working life to some/great extent.

- At a mean of 8.5 years post-diagnosis, $48 \%$ of survivors had changed from full-time to part-time employment. In multivariate analyses, immigration status (country of birth not Israel) was significantly associated with changing from full-time to part-time employment

- At 4 years post-diagnosis, $39 \%$ of survivors who were not employed were actively looking for work

- During 25-47 months post-diagnosis, survivors earned 9.0\% less than comparators. The difference was greatest for those with cancers of low survival.

- $13 \%$ of survivors who returned to work reported work changes due to cancer

- Work ability was higher among those working at survey than not working (mean $=7.3$ vs 3.6); $11 \%$ of those working vs $59 \%$ of those not working had poor physical work ability; $6 \%$ of those working vs $33 \%$ of those not working had poor mental work ability; change in work ability was lower among those working than those not working

- Among survivors who returned to work, $12 \%$ decreased and $3 \%$ increased working hours

- $21 \%$ reported a reduction in monthly income

- $11 \%$ reported perceived employer discrimination

- Among survivors employed at 3 years, hours worked per week in main/only and any second job were significantly lower than at diagnosis

- $19 \%$ of survivors (20\% of those disease-free and $13 \%$ of those not disease-free) vs $20 \%$ of comparators were employed in a different job than at diagnosis

- At 3 years, the increase in the proportion who earned $\$ 30,000+$ per annum (compared to at diagnosis) was similar in survivors and comparators

- In the third year from diagnosis, $23 \%$ of survivors were absent from work for $\geq 4$ weeks vs $19 \%$ of comparators. Average duration of absence was longer in survivors who were not disease free, compared to those who were disease free (4.1 weeks vs 2.1 weeks).

- At survey, $17 \%$ of survivors worked fewer hours than at diagnosis

- $20 \%$ of survivors who were employed at diagnosis and at 2 years took no sick leave

- Among survivors who returned to work, $52 \%$ reduced and 3\% increased working hours compared to at diagnosis

- Of survivors who resumed working, $36 \%$ returned after $\geq 60$ days absence. In multivariate analyses, receipt of chemotherapy was significantly related to returning after 60 days

- At 2-6 years post-diagnosis, female survivors aged 28-54 worked 3-4 hours less per week than similarly-aged females in comparison population; male survivors aged 28-54 worked 5-6 hours less than similarly-aged males in comparison population. Female survivors aged 55-65 worked 3-4 hours less per week than similarly-aged females in comparison population; male survivors aged 55-65 worked 3.5-5 hours less than similarly-aged males in comparison population

- Of survivors who had returned to work at 5 years, $32 \%$ had reduced working hours compared to diagnosis. In multivariate analysis, wages at diagnosis, sector of employment at diagnosis, chemotherapy, mental health score and chronic neuropathic pain were significantly associated with reduced working hours at 5 years

- Of survivors who resumed working, $36 \%$ had changed work (i.e. returned to adapted work or to other work). 
survivors reported reduced monthly income [39]. In contrast, at 3 years, the increase in the proportion who earned $\geq \$ 30,000$ per annum (compared to at diagnosis) was similar in survivors and comparators [40].

\section{Discussion}

\section{Summary of main findings}

This systematic review indicates that $73 \%$ of long-term cancer survivors who were working at diagnosis return to work and that long-term survivors are less likely to be working than people without cancer. However, there is significant heterogeneity in estimates of work retention between studies. Prognostic factors for not returning to work among longterm survivors include older age, lower income at diagnosis, comorbidities, receipt of chemotherapy, and lack of work adjustments, but these have been investigated in relatively few studies. In terms of other outcomes, a proportion of long-term survivors reduce their working hours compared to at diagnosis, and some make other work-related changes; they may also have reductions in income. However, these outcomes have been reported in few studies.

\section{Interpretation of results}

Our pooled estimate of the prevalence of work retention in long-term survivors is slightly higher than estimates of return to work from previous reviews which largely included studies of shorter-term survivors (Spelten et al., 62\% [18]; Mehnert, $64 \%$ [19]). For the current review, only studies in which all survivors were working at diagnosis were eligible for inclusion; this was not a requirement in previous reviews and could explain the apparently higher rate of work resumption observed here (since not working at diagnosis is a predictor of not working after cancer [44, 57]). Although some studies suggest that a longer period of work absence after a cancer diagnosis is associated with reduced likelihood of work resumption $[28,45]$, there is also evidence that rates of sickness absence post-cancer decrease over time and a proportion of those who are absent long-term eventually return to work [46, 58]. Thus, the higher rate of return to work in long-term survivor may be real.

To shed further light on this, we sought to investigate the temporal trajectory of work retention in long-term survivors. However, only five studies reported work resumption at more than one time-point (and three of these had a cross-sectional design) $[29,37,46,48,52]$, and information on work retention at 6 or more years post-diagnosis was only available from five studies which reported outcomes at a heterogeneous range of follow-up times (e.g., 5-7 years, 12 years, $>2$ years) $[31,34$, $38,43,55]$. Nonetheless, the meta-analysis suggested that there may be a modest trend in work retention-higher in years 3-3.9 than years 2-2.9 followed by a modest decline in later periods. This later decline is consistent with a recent Japanese study which showed that, among male cancer survivors, the rate of work continuation after return to work decreased steadily over time and that, on average, survivors continued working for only 4.5 years after work resumption [59].

The decline in work participation over time could reflect people dropping out of the workforce due to diagnosis of a second primary cancer or other cancer-related symptoms or late effects. Survivors who have returned to work can experience a range of physical or psychological after-effects which adversely impact their work ability or functioning $[60,61]$. In addition, cancer-related symptoms, such as fatigue, pain, and depression, have been associated with leaving the workforce after cancer, albeit mainly in shorter-term survivors [62-64]. Alternatively, the decline may simply reflect ageing and people reaching retirement age or opting for early retirement. While a significant proportion of cancer survivors want to retire early [65], and there is an excess risk of early retirement among survivors [66], some of those who do retire feel that they were forced into this rather than it being a free choice [32]. Further research is needed to clarify long-term temporal trajectories of work retention (and related outcomes, such as early retirement) among cancer survivors, and the factors influencing survivors' decisions to leave the workforce after initially resuming work.

We found a suggestion of geographical variation in work retention after cancer, with a lower prevalence in studies conducted outside North America and Europe. However, there was significant within-group heterogeneity so it is likely that the $P$ value from the test of between-group heterogeneity is too small [67]. Moreover, only three studies were included from outside Europe and North America, two from Brazil and one from Israel, and the largest of these included only 301 survivors $[34,39,55]$. Our rationale for grouping countries was that there is legislation intended to protect cancer survivors against discrimination at work in place in much of Europe [68] and North America (e.g., Americans with Disabilities Act [69]), but this may not be the situation elsewhere. Given this, it was striking that we found almost identical prevalence of work resumption in the studies from Europe and North America. This is consistent with conclusions from a 2009 meta-analysis of risk of unemployment in cancer survivors which reported no significant difference between Europe and the USA once cancer site, age, and background employment rate had been accounted for [2]. However, it is worth noting that the prevalences reported here from the European and North American studies varied widely (Europe: range 56\% [38] to $93 \%$ [33]; North America: 56\% [29] to 85\% [36]). This indicates the need for further large-scale studies of longterm survivors in all settings. 
The prognostic factors for work retention among long-term survivors identified here are broadly consistent with those reported in reviews which have mainly considered short-term work outcomes [18, 19, 70]. For example, in reviews of prognostic factors for return to work following breast or colorectal cancer, older age, receipt of chemotherapy, and presence of comorbidities were identified as inhibiting factors [71, 72], which we also found. Several other prognostic factors identified here- such as lack of work adjustments, self-employment, perceived value of work, and not having children - were seen in single studies and require confirmation.

\section{Strengths and limitations}

This is the first review to focus on long-term survivors, a group of growing size. We followed systematic review guidelines in conduct and reporting (PRISMA) [23] and used a valid and reliable tool to assess quality (MINORS) [27]. We minimized the possibility of missing relevant articles by searching multiple databases using terms designed to be sensitive and by reviewing reference lists of included papers and other reviews. To maximize comparability of estimates of prevalence of work retention across studies, we considered studies eligible only if all survivors were in paid work at the time of diagnosis. Despite this, there was heterogeneity in the estimates of work retention observed and it is likely that this was driven by the heterogeneity in study design and conduct. For example, authors used different terms for work retention (e.g., working, employed) but failed to define precisely what these meant (e.g., whether the "employed" group included people who were still on sick leave); most failed to state whether both full and part-time work was considered as working post-diagnosis; and most did not indicate whether they excluded some groups of survivors from follow-up (e.g., those with recurrent disease). All of these issues could have a significant impact on the estimate of work retention.

In addition, the quality appraisal indicated that none of the studies would be considered high quality. It is well recognized that studies of workforce participation after cancer should include non-cancer comparators to allow for the effect of cancer on workforce participation and general labor market trends to be distinguished [73]. Despite this, surprisingly, few studies (only 4) included non-cancer comparators. This contrasts with the 2009 systematic review of unemployment in cancer survivors which included 26 studies, all of which had non-cancer comparators [2]. Studies in the current review scored poorly in terms of lack of prospective design, failure to report a priori sample size calculations and failure to report loss to follow-up. In addition, work retention was self-reported in 20 of the 21 studies, using a variety of data collection methods and instruments/questions; none of these instruments/questions appeared to have been rigorously validated. Most studies were small — only six included more than 500 survivors [35, 36, 40, 44, 48, 52]. Eight included a mixed group of cancer survivors (and insufficient numbers to allow sitespecific analyses) [28, 31, 36, 43, 44, 46, 48, 51, 52], even though cancer site is likely to be a significant prognostic factor for work-related outcomes [59, 70].

Considering the evidence-base as a whole, this review indicates that important gaps remain around work retention in long-term cancer survivors. Little is known about patterns and predictors of long-term work retention in most countries beyond North America and selected European populations. System-level factors (e.g., social welfare provisions, insurance, legal provisions) are likely to be important influences on work outcomes among cancer survivors [74], but have not been investigated as influences among long-term survivors. Little is known about most cancers, other than breast (most of the studies of mixed cancer sites were dominated by breast cancer). Little is known about how work retention - and other work-related outcomes (such as income)_evolve over time in long-term survivors.

\section{Future directions: Research}

High-quality, population-based, longitudinal studies, which include non-cancer comparators, are needed to fill the evidence gaps identified by this review and clarify the work retention trajectory in long-term cancer survivors. While studies involving primary data collection would be useful (as they allow collection of detailed data about work outcomes and prognostic factors), studies which involve linkage of administrative and health datasets would also be of considerable value (see, for example, Grinshpun [57], Jeon [36], Heinesen [75]). This review also indicates a clear need for harmonization of data and methods across the research community. In particular, there is an urgent need to develop standard instruments to assess work retention (and other work-related outcomes) which could be used internationally. The European CANWON network [76] has embarked on a consensus process to develop such a tool. Initiatives to pool patient-level data from studies in different settings could also be of value in understanding system-level drivers.

\section{Future directions: Practice}

The findings of this review - particularly regarding the proportion of survivors who retain work long-term - are relevant for patients and patient advocacy groups, and for cancer clinicians, oncology nurses, general physicians, and occupational health care professionals who counsel and advise cancer patients. Professionals may also consider focussing support efforts on those subgroups of survivors most likely to have poor long-term work retention outcomes. The findings are also pertinent for the development and update of oncological guidelines on cancer survivorship care. 


\section{Conclusions}

This systematic review indicates that $73 \%$ of long-term cancer survivors who were working at diagnosis return to work, and that long-term survivors are less likely to be working than people without cancer. Prognostic factors for not returning to work among long-term survivors include older age, lower income at diagnosis, comorbidities, and receipt of chemotherapy, but these have been investigated in relatively few studies. High-quality, population-based, longitudinal studies, which include non-cancer comparators, are needed to fill the evidence gaps identified by this review and clarify the work retention trajectory in long-term cancer survivors.

Funding information This paper was supported by European Union COST Action Cancer and Work Network (CANWON) IS1211.

\section{Compliance with ethical standards}

Conflict of interest The authors declare that they have no conflicts of interest.

Ethical approval This article does not contain any studies with human participants performed by the authors.

Open Access This article is licensed under a Creative Commons Attribution 4.0 International License, which permits use, sharing, adaptation, distribution and reproduction in any medium or format, as long as you give appropriate credit to the original author(s) and the source, provide a link to the Creative Commons licence, and indicate if changes were made. The images or other third party material in this article are included in the article's Creative Commons licence, unless indicated otherwise in a credit line to the material. If material is not included in the article's Creative Commons licence and your intended use is not permitted by statutory regulation or exceeds the permitted use, you will need to obtain permission directly from the copyright holder. To view a copy of this licence, visit http://creativecommons.org/licenses/by/4.0/.

\section{References}

1. Ferlay J, Ervik M, Lam F, Colombet M, Mery L, Piñeros M, Znaor A, Soerjomataram I, Bray F. Global Cancer Observatory: Cancer Today. Lyon, France: International Agency for Research on Cancer. 2018. Available from: https://gco.iarc.fr/today. Accessed 26/11/ 2019.

2. de Boer AG, Taskila T, Ojajarvi A, van Dijk FJ, Verbeek JH. Cancer survivors and unemployment: a meta-analysis and meta-regression. JAMA. 2009;301:753-62.

3. Wells M, Amir Z, Cox T, Eva G, Greenfield D, Hubbard G, et al. Time to act: the challenges of working during and after cancer, initiatives in research and practice. Eur J Oncol Nurs. 2014;18:1-2.

4. Torp S, Paraponaris A, Van Hoof E, Lindbohm ML, Tamminga SJ, Alleaume $\mathrm{C}$, et al. Work-related outcomes in self-employed Cancer survivors: a European multi-country study. J Occup Rehabil. 2019;29:361-74.

5. Désiron HA, Crutzen R, Godderis L, Van Hoof E, de Rijk A. Bridging health care and the workplace: formulation of a return- to-work intervention for breast Cancer patients using an intervention mapping approach. J Occup Rehabil. 2016;26(3):350-65.

6. Bradley CJ, Brown KL, Haan M, Glasgow RE, Newman LS, Rabin B, et al. Cancer survivorship and employment: intersection of Oral agents, changing workforce dynamics, and Employers' perspectives. J Natl Cancer Inst. 2018;110(12):1292-9.

7. de Boer AG, Verbeek JH, Spelten ER, Uitterhoeve AL, Ansink AC, de Reijke TM, et al. Work ability and return-to-work in cancer patients. Br J Cancer. 2008;98:1342-7.

8. Taskila T, de Boer AG, van Dijk FJ, Verbeek JH. Fatigue and its correlates in cancer patients who had returned to work-a cohort study. Psychooncology. 2011;20:1236-41.

9. Kline RM, Arora NK, Bradley CJ, Brauer ER, Graves DL, Lunsford NB, et al. Long-term survivorship care after Cancer treatment - summary of a 2017 National Cancer Policy Forum Workshop. J Natl Cancer Inst. 2018;110(12):1300-10.

10. Sharp L, O'Leary E, Kinnear H, Gavin A, Drummond FJ. Cancerrelated symptoms predict psychological wellbeing among prostate cancer survivors: results from the PiCTure study. Psychooncology. 2016;25:282-91.

11. Kozelj M, Zver S, Zadnik V. Long term follow-up report of cardiac toxicity in patients with multiple myeloma treated with tandem autologous hematopoietic stem cell transplantation. Radiol Oncol. 2013;47:161-5.

12. Munir F, Kalawsky K, Lawrence C, Yarker J, Haslam C, Ahmed S. Cognitive intervention for breast cancer patients undergoing adjuvant chemotherapy: a needs analysis. Cancer Nurs. 2011;34(5): 385-92.

13. Dorland HF, Abma FI, Roelen CA, Smink A, Feuerstein M, Amick $\mathrm{BC}$, et al. The cognitive symptom checklist-work in cancer patients is related with work functioning, fatigue and depressive symptoms: a validation study. J Cancer Surviv. 2016;10:545-52.

14. Horsboel TA, Bültmann U, Nielsen CV, Nielsen B, Andersen NT, de Thurah A. Are fatigue, depression and anxiety associated with labour market participation among patients diagnosed with haematological malignancies? A prospective study. Psychooncology. 2015;24:408-15.

15. Paalman CH, van Leeuwen FE, Aaronson NK, de Boer AG, van de Poll-Franse L, Oldenburg HS, et al. Employment and social benefits up to 10 years after breast cancer diagnosis: a population-based study. Br J Cancer. 2016;114:81-7.

16. Noeres D, Park-Simon TW, Grabow J, Sperlich S, KochGießelmann H, Jaunzeme J, et al. Return to work after treatment for primary breast cancer over a 6-year period: results from a prospective study comparing patients with the general population. Support Care Cancer. 2013;21:1901-9.

17. Rottenberg Y, Ratzon NZ, Jacobs JM, Cohen M, Peretz T, de Boer AG. Unemployment risk and income change after testicular cancer diagnosis: A population-based study. Urol Oncol. 2016;34:5.e2733.

18. Spelten ER, Sprangers MAG, Verbeek JH. Factors reported to influence the return to work of cancer survivors: a literature review. Psychooncology. 2002;11:124-31.

19. Mehnert A. Employment and work-related issues in cancer survivors. Crit Rev Oncol Hematol. 2011;77:109-30.

20. Paltrinieri S, Fugazzaro S, Bertozzi L, Bassi MC, Pellegrini M, Vicentini M, et al. Return to work in European Cancer survivors: a systematic review. Support Care Cancer. 2018;26(9):2983-94.

21. Tamminga SJ, Bültmann U, Husson O, Kuijpens JL, Frings-Dresen $\mathrm{MH}$, de Boer AG. Employment and insurance outcomes and factors associated with employment among long-term thyroid cancer survivors: a population-based study from the PROFILES registry. Qual Life Res. 2016;25:997-1005.

22. de Moor JS, Alfano CM, Kent EE, Norton WE, Coughlan D, Roberts MC, et al. Recommendations for research and practice to 
improve work outcomes among Cancer survivors. J Natl Cancer Inst. 2018;110(10):1041-7.

23. Moher D, Liberati A, Tetzlaff J, Altman DG, PRISMA Group. Preferred reporting items for systematic reviews and meta-analyses: the PRISMA statement. J Clin Epidemiol. 2009;62:1006-24.

24. Burg MA, Adorno G, Lopez ED, Loerzel V, Stein K, Wallace C, et al. Current unmet needs of cancer survivors: analysis of openended responses to the American Cancer Society study of Cancer survivors II. Cancer. 2015;121(4):623-30.

25. Nyaga VN, Arbyn M, Aerts M. Metaprop: a Stata command to perform meta-analysis of binomial data. Arch Public Health. 2014;72:e39.

26. Cancer Today. Data and Methods. https://gco.iarc.fr/today/datasources-methods\#population-dictionnary. Accessed 6/10/2019.

27. Slim K, Nini E, Forestier D, Kwiatkowski F, Panis Y, Chipponi J. Methodological index for non-randomized studies (minors): development and validation of a new instrument. ANZ J Surg. 2003;73: $712-6$.

28. Amir Z, Moran T, Walsh L, Iddenden R, Luker K. Return to paid work after cancer: a British experience. J Cancer Surviv. 2007;1: 129-36.

29. Blinder VS, Patil S, Thind A, Diamant A, Hudis CA, Basch E, et al. Return to work in low-income Latina and non-Latina white breast cancer survivors: a 3-year longitudinal study. Cancer. 2012;118: 1664-74.

30. Blinder V, Patil S, Eberle C, Griggs J, Maly RC. Early predictors of not returning to work in low-income breast cancer survivors: a 5year longitudinal study. Breast Cancer Res Treat. 2013;140:40716.

31. Bradley CJ, Bednarek HL. Employment patterns of long-term cancer survivors. Psychooncology. 2002;11:188-98.

32. Bednarek HL, Bradley CJ. Work and retirement after cancer diagnosis. Res Nurs Health. 2005;28:126-35.

33. Dahl S, Loge JH, Berge V, Dahl AA, Cvancarova M, Fosså SD. Influence of radical prostatectomy for prostate cancer on work status and working life 3 years after surgery. J Cancer Surviv. 2015;9: 172-9.

34. Hamood R, Hamood H, Merhasin I, Keinan-Boker L. Work transitions in breast Cancer survivors and effects on quality of life. J Occup Rehabil. 2019;29:336-49.

35. Jagsi R, Hawley ST, Abrahamse P, Li Y, Janz NK, Griggs JJ, et al. Impact of adjuvant chemotherapy on long-term employment of survivors of early-stage breast cancer. Cancer. 2014;120:1854-62.

36. Jeon SH. The long-term effects of Cancer on employment and earnings. Health Econ. 2017;26(5):671-84.

37. Johnsson A, Fornander T, Olsson M, Nystedt M, Johansson H, Rutqvist LE. Factors associated with return to work after breast cancer treatment. Acta Oncol. 2007;46:90-6.

38. Kiserud CE, Fagerli UM, Smeland KB, Fluge Ø, Bersvendsen H, Kvaløy S, et al. Pattern of employment and associated factors in long-term lymphoma survivors 10 years after high-dose chemotherapy with autologous stem cell transplantation. Acta Oncol. 2016;55:547-53.

39. Landeiro LCG, Gagliato DM, Fêde AB, Fraile NM, Lopez RM, da Fonseca LG, et al. Return to work after breast cancer diagnosis: an observational prospective study in Brazil. Cancer. 2018;124(24): 4700-10.

40. Maunsell E, Drolet M, Brisson J, Brisson C, Mâsse B, Deschênes L. Work situation after breast cancer: results from a population-based study. J Natl Cancer Inst. 2004;96:1813-22.

41. Drolet M, Maunsell E, Mondor M, Brisson C, Brisson J, Mâsse B, et al. Work absence after breast cancer diagnosis: a populationbased study. CMAJ. 2005;173:765-71.

42. Drolet M, Maunsell E, Brisson J, Brisson C, Mâsse B, Deschênes L. Not working 3 years after breast cancer: predictors in a populationbased study. J Clin Oncol. 2005;23:8305-12.
43. Mols F, Thong MS, Vreugdenhil G, van de Poll-Franse LV. Longterm cancer survivors experience work changes after diagnosis: results of a population-based study. Psychooncology. 2009;18: 1252-60.

44. Paraponaris A, Teyssier LS, Ventelou B. Job tenure and selfreported workplace discrimination for cancer survivors 2 years after diagnosis: does employment legislation matter? Health Policy. 2010;98:144-55.

45. Marino P, Teyssier LS, Malavolti L, Le Corroller-Soriano AG. Sex differences in the return-to-work process of cancer survivors 2 years after diagnosis: results from a large French population-based sample. J Clin Oncol. 2013;31:1277-84.

46. Pearce A, Timmons A, O'Sullivan E, Gallagher P, Gooberman-Hill $\mathrm{R}$, Thomas AA, et al. Long-term workforce participation patterns following head and neck cancer. J Cancer Surviv. 2015;9:30-9.

47. Sanchez KM, Richardson JL, Mason HR. The return to work experiences of colorectal cancer survivors. AAOHN J. 2004;52:500 10 .

48. Short PF, Vasey JJ, Tunceli K. Employment pathways in a large cohort of adult cancer survivors. Cancer. 2005;103:1292-301.

49. Farley Short P, Vasey JJ, Moran JR. Long-term effects of cancer survivorship on the employment of older workers. Health Serv Res. 2008;43(1 Pt 1):193-210.

50. Moran JR, Short PF, Hollenbeak CS. Long-term employment effects of surviving cancer. J Health Econ. 2011;30(3):505-14.

51. Tevaarwerk AJ, Lee JW, Sesto ME, Buhr KA, Cleeland CS, Manola J, et al. Employment outcomes among survivors of common cancers: the symptom outcomes and practice patterns (SOAPP) study. J Cancer Surviv. 2013;7:191-202.

52. Tison A, Sagaon-Teyssier L, Sansonetti C, Blatier JF. Paraponaris a; VICAN 2 group. Transitions in the labor market after cancer: a comparison of self-employed workers and salaried staff. Support Care Cancer. 2016;24:4879-86.

53. Alleaume C, Bendiane MK, Bouhnik AD, Rey D, Cortaredona S, Seror V, et al. Chronic neuropathic pain negatively associated with employment retention of cancer survivors: evidence from a national French survey. J Cancer Surviv. 2018;12(1):115-26.

54. van den Brink M, van den Hout WB, Kievit J, Marijnen CA, Putter $\mathrm{H}$, van de Velde $\mathrm{CJ}$, et al. The impact of diagnosis and treatment of rectal cancer on paid and unpaid labor. Dis Colon Rectum. 2005;48: 1875-82.

55. Vartanian JG, Carvalho AL, Toyota J, Kowalski IS, Kowalski LP. Socioeconomic effects of and risk factors for disability in long-term survivors of head and neck cancer. Arch Otolaryngol Head Neck Surg. 2006;132:32-5.

56. Verdonck-de Leeuw IM, van Bleek WJ, Leemans CR, de Bree R. Employment and return to work in head and neck cancer survivors. Oral Oncol. 2010;46:56-60.

57. Grinshpun A, Rottenberg Y. Unemployment following breast cancer diagnosis: a population-based study. Breast. 2019;44:24-8.

58. Kvillemo P, Mittendorfer-Rutz E, Bränström R, Nilsson K, Alexanderson K. Sickness absence and disability pension after breast Cancer diagnosis: a 5 -year Nationwide cohort study. J Clin Oncol. 2017:35(18):2044-52.

59. Endo M, Haruyama Y, Muto G, Kiyohara K, Mizoue T, Kojimahara $\mathrm{N}$, et al. Work sustainability among male Cancer survivors after returning to work. J Epidemiol. 2018;28(2):88-93.

60. Duijts SF, van Egmond MP, Spelten E, van Muijen P, Anema JR, van der Beek AJ. Physical and psychosocial problems in cancer survivors beyond return to work: a systematic review. Psychooncology. 2014;23(5):481-92.

61. Dorland HF, Abma FI, Van Zon SKR, Stewart RE, Amick BC, Ranchor AV, et al. Fatigue and depressive symptoms improve but remain negatively related to work functioning over 18 months after return to work in cancer patients. J Cancer Surviv. 2018;12(3):3718. 
62. Ekenga CC, Pérez M, Margenthaler JA, Jeffe DB. Early-stage breast cancer and employment participation after 2 years of follow-up: a comparison with age-matched controls. Cancer. 2018;124(9):2026-35.

63. Bennett D, Kearney T, Donnelly DW, Downing A, Wright P, Wilding $\mathrm{S}$, et al. Factors influencing job loss and early retirement in working men with prostate cancer-findings from the populationbased life after prostate Cancer diagnosis (LAPCD) study. J Cancer Surviv. 2018;12(5):669-78.

64. Lindbohm ML, Kuosma E, Taskila T, Hietanen P, Carlsen K, Gudbergsson S, et al. Early retirement and non-employment after breast cancer. Psychooncology. 2014;23(6):634 41.

65. Mehnert A, Barth J, Gaspar M, Leibbrand B, Kegel CD, Bootsveld $\mathrm{W}$, et al. Predictors of early retirement after cancer rehabilitation-a longitudinal study. Eur J Cancer Care (Engl). 2017;26(5).

66. Carlsen K, Oksbjerg Dalton S, Frederiksen K, Diderichsen F, Johansen C. Cancer and the risk for taking early retirement pension: a Danish cohort study. Scand J Public Health. 2008;36(2):117-25.

67. Harris RJ, Deeks JJ, Altman DG, Bradburn MJ, Harbord RM. Metan: fixed- and random-effects meta-analysis. Stata J. 2008;8(1):3-28.

68. EUR-Lex. Access to European Union Law. Council Directive 2000/78/EC of 27 November 2000 establishing a general framework for equal treatment in employment and occupation. https:// eur-lex.europa.eu/legal-content/EN/TXT/?uri=CELEX: 32000L0078 Accessed 06/10/2019.

69. Feuerstein M, Gehrke AK, McMahon BT, McMahon MC, Challenges persist under Americans with disabilities act amendments act: how can oncology providers help? J Oncol Pract. 2017;13(6):e543-51.

70. van Muijen P, Weevers NL, Snels IA, Duijts SF, Bruinvels DJ, Schellart AJ, et al. Predictors of return to work and employment in cancer survivors: a systematic review. Eur J Cancer Care (Engl). 2013;22(2):144-60.

71. Islam T, Dahlui M, Majid HA, Nahar AM, Mohd Taib NA, Su TT. MyBCC study group. Factors associated with return to work of breast cancer survivors: a systematic review. BMC Public Health. 2014;14(Suppl 3):S8

72. den Bakker CM, Anema JR, Zaman AGNM, de Vet HCW, Sharp L, Angenete E, et al. Prognostic factors for return to work and work disability among colorectal cancer survivors; a systematic review. PLoS One. 2018;13(8):e0200720.

73. Bradley CJ, Neumark D, Luo Z, Schenk M. Employment and cancer: findings from a longitudinal study of breast and prostate cancer survivors. Cancer Investig. 2007;25(1):47-54.

74. Sharp L, Timmons A. Social welfare and legal constraints associated with work among breast and prostate cancer survivors: experiences from Ireland. J Cancer Surviv. 2011;5(4):382-94.

75. Heinesen E, Imai S, Maruyama S. Employment, job skills and occupational mobility of cancer survivors. J Health Econ. 2018;58:151-75.

76. de Boer AG. The European Cancer and work network: CANWON. J Occup Rehabil. 2014;24(3):393-8.

Publisher's note Springer Nature remains neutral with regard to jurisdictional claims in published maps and institutional affiliations. 